\title{
Validation of an Arabic version of the Yale Food Addiction Scale 2.0
}

Mounir Fawzi ${ }^{1}$ and Mohab Fawzi ${ }^{1}$

Department of Psychiatry, Faculty of Medicine, Zagazig University, Zagazig, Egypt (Correspondence to: Mounir H. Fawzi: mounir.fawzi40@gmail. com).

\begin{abstract}
Background: The Yale Food Addiction Scale (YFAS) is the gold standard for assessment of food addiction based on the Diagnostic and Statistical Manual of Mental Disorders (DSM). To keep up with the DSM-5 update, the YFAS 2.0 was published in early 2016.

Aims: We conducted the present study to translate, adapt and validate the DSM-5 Yale Food Addiction Scale 2.0 for use with Arabic speakers.

Methods: Both the final YFAS 2.0-A, developed with a rigorous methodology, and the English YFAS 2.0 were completed by 236 Egyptian medical students fluent in English and Arabic. Three weeks later, the YFAS 2.0-A was readministered to all participants.

Results: Cronbach's alpha for the YFAS 2.0-A was 0.89. The 3-week intraclass correlation coefficients for diagnosis and symptom scores were 0.95 and 0.93 , respectively. Weighted kappa statistics ranged from 0.66 to $0.95(P<0.001)$.

Conclusions: Our findings indicate that the Arabic YFAS 2.0-A is a reliable tool, and that it is valid for use as equivalent to the English YFAS 2.0 in the investigation of food addiction among Arabic-speaking populations.

Keywords: Arabic version; YFAS; food addiction; validity

Citation: Fawzi M; Fawzi M. Validation of an Arabic version of the Yale Food Addiction Scale 2.0. East Mediterr Health J. 2018;24(8):745-752. https://doi. $\operatorname{org} / 10.26719 / 2018.24 .8 .745$

Received: 10/04/17; accepted: 25/07/17

Copyright (c) World Health Organization (WHO) 2018. Some rights reserved. This work is available under the CC BY-NC-SA 3.o IGO license (https:// creativecommons.org/licenses/by-nc-sa/3.o/igo).
\end{abstract}

\section{Introduction}

Recently, food addiction has sparked unprecedented interest among the scientific and lay media. This may give an impression that the topic is exclusively a product of the 21st century in which the increasing availability of highly processed foods may at least partly help explain the contemporary serious increase of overeating and obesity rates (1). But in fact, it is not a new idea that food can be addictive. It is 60 years since Theron G. Randolph defined the term food addiction as "a specific adaptation to one or more regularly consumed foods to which a person is highly sensitive, produces a common pattern of symptoms descriptively similar to those of other addictive processes" (2).

Food addiction has for decades been a matter of controversy, albeit with sporadic production of scientific literature. One reason for the lack of consensus was the lack of measurable construct of food addiction. In order to help appraisal of the food addiction construct using a standardized measure, Yale Food Addiction Scale (YFAS) was devised in 2009 (3). Attention to the subject dramatically intensified after the appearance of the YFAS, as reflected in the sharp rise of the number of studies on food addiction since 2009 (4).

The original YFAS assesses addiction to foods by transforming the 7 DSM-IV-TR diagnostic criteria for substance dependence (5) to exhibit eating behaviours associated with foods high in sugar, fat and salt. An initial validation study in a sample of university students showed a single factor structure and adequate reliability and validity (3). Relative stability and reliability over time in a nonclinical population was also demonstrated (6). The good psychometric properties of the YFAS were replicated in subsequent studies using nonclinical and clinical samples $(7,8)$. Since its first appearance, the YFAS, has been the tool used in most of the food addiction researches (9), and for many studies in this field it is the gold standard (10).

The worldwide interest in measuring the food addiction construct with a psychometrically validated tool has led to the translation of the YFAS into many languages including French, German, Spanish, Italian and Chinese (10-14).

To keep up with the update of the DSM-5 (15), the YFAS 2.0 was developed. Like its predecessors, this new version was found to be a psychometrically sound tool (16). German and French versions have appeared recently, replicating the good psychometric properties of the other versions $(17,18)$.

However, a validated food addiction measure is still unavailable in the Arabic-speaking countries. As a result, important related issues such as the emerging unhealthy eating habits (19) could not be adequately investigated, despite their practical implication in the alarming increases in rates of obesity and type 2 diabetes mellitus currently prevailing throughout the Eastern Mediterranean Region $(20,21)$. In Kuwait, for example, the English YFAS version (3) was applied without translation 
or adaptation to a sample of students who could read and write in English (22). In Egypt, an attempt was made to translate this earlier English version of the YFAS into Arabic (23) but validation data of the translation process have not been published.

We believe that up to now no Arabic version of the YFAS 2.0 has been produced. Therefore, we aimed in this study to translate, adapt and validate the DSM-5 Yale Food Addiction Scale 2.0 for use with Arabic-speaking individuals.

\section{Methods}

\section{Participants}

At the beginning of the 2016-2017 academic year, we recruited 270 consenting Egyptian bilingual (English and Arabic) second-year medical students as volunteers from Zagazig University, Egypt, by convenience sampling. Thirty of these students were recruited for pretesting the final Arabic version. The rest of participants were subjected to the study measures and 3 "catch" questions intended for testing participants' attention to survey content. In the first session of the study, 4 students failed to answer $\geq 1$ of these questions in English and/or Arabic. They were excluded, leaving data from 236 participants for the main study analysis.

\section{Measures}

The YFAS 2.0 is a 35 -item self-report Likert-type scale with 8 frequency response options for each item, ranging from "Never" to "Every Day" (22). It assesses respondent's addictive-like eating behaviour in accordance with the following symptom criteria of the DSM-5 Substance-Related and Addictive Disorders:

- Substance taken in larger amount and for longer period than intended (Items 1,2,3);

- Persistent desire or repeated unsuccessful attempts to quit (items 4,25,31,32);

- Much time/activity to obtain, use, recover (items $5,6,7)$.

- Important social, occupational, or recreational activities given up or reduced (items 8,10,18,20);

- Use continues despite knowledge of adverse consequences (e.g., emotional problems, physical problems) (items, 22,23);

- Tolerance (marked increase in amount; marked decrease in effect) (items 24,26);

- Characteristic withdrawal symptoms; substance taken to relieve withdrawal (Items 11,12,13,14,15);

- Continued use despite social or interpersonal problems (items 9,21,35);

- Failure to fulfil major role obligation (e.g., work, school, home) (items 19,27);

- Use in physically hazardous situations (items 28,33,34);

- Craving, or a strong desire or urge to use (items 29,30);
- Use causes clinically significant impairment or distress (items 16,17).

There are 2 summary scores, first symptom count scoring, which is computed by the number of symptom criteria met in the past year. A symptom criterion is met if $\geq 1$ item under this criterion is scored as 1. Each item has a specific cut-off, which ranges from once a month to $4^{-6}$ times a week. Criterion 12, which assesses impairment or distress resulting from overeating (items 16,17 ) is not included in the symptom count score. Therefore, symptom count scoring should range from $\mathrm{o}$ to 11 . The second summary score is for a dichotomous diagnosis of food addiction with severity level according to the number of symptom criteria met in the past year: mild ( $2-3$ criteria), moderate (4-5 criteria), and severe addiction ( $\geq 6$ criteria). Significant clinical impairment or distress should be also endorsed to make any food addiction diagnosis.

\section{Translation process for the Arabic version of YFAS 2.0 (YFAS 2.0-A)}

The translation process of the YFAS 2.0 in this study was conducted along the lines that we described previously (24). In brief, 2 bilingual psychiatrists independently translated the English YFAS 2.o version into Arabic. The 2 translations were merged into 1 reconciled version by an Egyptian panel of 3 psychiatrists and 2 translators. Emphasis was placed on conceptual and cultural equivalence rather than on literal translation. The resulting version was then translated back into English by 2 other translators who had not previously seen the original YFAS. We compared the back-translated versions with the original, and discrepancies were addressed to produce a final version, which was tested for understandability and acceptability in a small pilot study. Results suggested that no further changes were needed. A copy of the instrument (YFAS 2.0-A) may be requested from the corresponding author.

To maintain consistency with the original English YFAS and the YFAS 2.0, we followed the same scoring procedure suggested by their authors $(3,16)$.

\section{Catch questions}

Three catch questions similar to those suggested by Gearhardt et al. (16) were included in English at the end of the YFAS 2.0, and in Arabic at the end of the YFAS 2.0-A. Answers to all 3 questions in both languages should be "Never", otherwise the participant was judged as not carefully reading the questions.

\section{Study procedures}

In the initial session of the main study, participants completed the original YFAS 2.0 (English) (16), then they completed the Arabic version (YFAS 2.0-A) (in the same session). Additionally, participants provided basic demographic information and self-report of height and weight for the body mass index (BMI) computation.

Participants were also asked to respond again to the YFAS 2.0-A after a gap of 3 weeks under conditions as similar as possible to those of the first session. 


\section{Data analysis}

Descriptive statistics were used to report participants' demographic data. The internal consistency reliability of the YFAS 2.0-A scale was evaluated with Kuder-Richardson alpha (KR-20) and Cronbach's alpha. A Cronbach's alpha value greater than 0.70 was considered acceptable (25). Corrected item-total correlation and Cronbach's alpha if item deleted were also computed. A value of more than 0.4 for the corrected item-total correlation or a decrease in Cronbach's alpha if item deleted value is considered an indication of the high contribution of an item to the scale.

Repeatability (test-retest reliability) of the YFAS 2.0A scale was assessed using the intraclass correlation coefficients (ICC), based on consistency 2-way mixed single measures [ICC $(3,1)$ or ICC $(C, 1)$ ], along with the $95 \%$ confidence interval. The ICC was interpreted as poor for values $<0.5$, moderate for values between 0.5 and 0.75 and good for ICC values > 0.75) (26).

Spearman's rank correlation coefficient, rho $(\rho)$, was also used. Cohen's weighted kappa statistics were applied to analyse the agreement between the Arabic and English YFAS 2.0 versions. Strength of agreement was evaluated according to the following criteria: poor agreement $(\mathrm{K}<$ $0.20)$, fair agreement $(\mathrm{K}=0.21-0.40)$, moderate agreement $(\mathrm{K}=0.41-0.60)$, good agreement $(\mathrm{K}=0.61-0.80)$ and very good agreement $(\mathrm{K}>0.80)$ (27). Participants with and without a YFAS 2.0 or YFAS 2.0-A diagnosis were compared with Mann-Whitney U-tests.

Statistical analyses were performed with Microsoft Excel and SPSS, version 19.0.1. Significance level for all analyses was set at the $5 \%$ level.

\section{Ethical considerations}

Ethical approval to conduct the study was obtained from the research ethics committee at the Faculty of Medicine, Zagazig University. Before completing questionnaires, written informed consent was obtained from all participants, including those who participated in the pilot study.

\section{Results}

Out of 236 participants who were included in the main study analysis, 126 (53.4\%) were females, mean age 19.1 [standard deviation (SD) 1.2] years and 110 (46.6\%) were males, mean age 19.3 (SD 1.3) years. The average self-reported BMI was 22.3 (SD 4.1) kg/m² and 22.1 (SD 3.9) kg/ $\mathrm{m}^{2}$ for female and male students, respectively. Using the YFAS 2.0-A, 26 (11.0\%) of participants met the threshold for food addiction diagnosis. Nine (3.8\%) met criteria for diagnosis of a mild, $5(2.1 \%)$ a moderate, and $12(5.1 \%)$ a severe food addiction. Two participants with mild food addiction diagnosis on the YFAS 2.0-A did not meet the criteria for diagnosis on the English YFAS 2.o. Four of the participants who did not meet a diagnosis threshold on the YFAS 2.0-A qualified for mild diagnosis on YFAS 2.0. Participants with a YFAS 2.0 diagnosis had a significantly higher BMI (median $\left.=24.3 \mathrm{~kg} / \mathrm{m}^{2}\right)$ than those without diagnosis $\left(\right.$ median $\left.=21.5 \mathrm{~kg} / \mathrm{m}^{2}\right)($ Mann-Whitney $U=$
1432.000; $Z=-3.971 ; P$ 2-tailed < 0.001).

The Kuder-Richardson alpha for the entire YFAS 2.0-A scale was 0.89. A similar result was obtained for the Cronbach alpha. Table 1 demonstrates the internal consistency reliability for this scale. All item-total correlation coefficients were greater than 0.50. As shown in the alpha if item deleted column, none of the values was greater than the overall alpha.

Good test-retest reliability was demonstrated for the YFAS 2.0-A diagnosis (ICC $=0.95$; Spearman $\rho=0.95$ ) and total symptom scores ( $\mathrm{ICC}=0.93$; Spearman $\rho=0.94$ ) (Table 2). The ICC values for the individual symptoms ranged from 0.60 to 0.92 , with symptom 1 (Food taken in larger amount and for longer period than intended) showing the greatest repeatability (ICC $=0.92)$.

Comparison between scores on the Arabic and English versions for all the YFAS 2.0 items is presented in Table 3. Weighted kappa statistics ranged from 0.66 (Item 4) to 0.95 (Total symptom score), indicating good to very good agreement $(P<0.001$ for all items).

\section{Discussion}

This study aimed to produce an Arabic version of the YFAS 2.0. A rigorous methodology was applied for translation/back translation and final approval of the Arabic version of the YFAS 2.0 (YFAS 2.0-A). During this process, cross-cultural adaptation was performed with emphasis on the similarity of meaning rather than the similarity of linguistic form. Both the final YFAS 2.0-A and the original English version were then completed by 236 Egyptian medical students. The $100 \%$ response rate for each item indicated that all items were easily understood and acceptable.

In the current study, Cronbach's alpha for the entire YFAS 2.0-A scale was 0.89. We also found that all itemtotal correlation coefficients were $>0.50$, and that the Cronbach's alpha if items are deleted for each item did not exceed the overall Cronbach's alpha level of 0.89. All this indicates that the internal consistency reliability of the items of YFAS 2.0-A is well accepted and consistent with the original English version (16), and with translated versions in other languages $(17,18)$. In addition, good testretest reliability was demonstrated. The 3 -week ICC for diagnosis was 0.95, and that for symptom scores was 0.93. This is in keeping with other studies, which indicate that the diagnosis and symptom scores are stable over periods of several weeks (14). However, stability over longer periods has not been sufficiently investigated because most of studies are cross-sectional. Yet, the study by Pursey et al. (6), which extended over a period of 18 months, reported a rather lower ICC than ours (0.71 for diagnosis and 0.72 for symptom scores).

We also wanted to examine the extent of agreement between the Arabic and English YFAS 2.0 versions to find out how similar they are. A widely used method for such purpose is Cohen's kappa coefficient, which takes into consideration the amount of agreement expected by chance. Yet, Cohen's kappa is only appropriate for binary 


\begin{tabular}{|c|c|c|}
\hline \multirow[t]{2}{*}{ Item } & Corrected item-total correlation & Alpha if item deleted \\
\hline & \multicolumn{2}{|c|}{ Food taken in larger amount and for longer period than intended } \\
\hline Item 1 & 0.77 & 0.81 \\
\hline Item 2 & 0.68 & 0.81 \\
\hline \multirow[t]{2}{*}{ Item 3} & 0.66 & 0.82 \\
\hline & \multicolumn{2}{|c|}{ Persistent desire or repeated unsuccessful attempts to quit } \\
\hline Item 4 & 0.75 & 0.87 \\
\hline Item 25 & 0.85 & 0.87 \\
\hline Item 31 & 0.76 & 0.85 \\
\hline \multirow[t]{2}{*}{ Item 32} & 0.73 & 0.85 \\
\hline & \multicolumn{2}{|c|}{ Much time/activity to obtain, use or recover from effects of food } \\
\hline Item 5 & 0.74 & 0.86 \\
\hline Item 6 & 0.61 & 0.85 \\
\hline \multirow[t]{2}{*}{ Item 7} & 0.58 & 0.85 \\
\hline & \multicolumn{2}{|c|}{ Important social, occupational, or recreational activities given up or reduced } \\
\hline Item 8 & 0.72 & 0.87 \\
\hline Item 10 & 0.75 & 0.87 \\
\hline Item 18 & 0.60 & 0.85 \\
\hline \multirow[t]{2}{*}{ Item 20} & 0.52 & 0.86 \\
\hline & \multicolumn{2}{|c|}{ Use continues despite knowledge of adverse consequences } \\
\hline Item 22 & 0.71 & 0.85 \\
\hline \multirow[t]{2}{*}{ Item 23} & 0.63 & 0.86 \\
\hline & \multicolumn{2}{|c|}{ Tolerance } \\
\hline Item 24 & 0.83 & 0.86 \\
\hline \multirow[t]{2}{*}{ Item 26} & 0.84 & 0.87 \\
\hline & \multicolumn{2}{|c|}{ Withdrawal } \\
\hline Item 11 & 0.78 & 0.86 \\
\hline Item 12 & 0.83 & 0.87 \\
\hline Item 13 & 0.83 & 0.86 \\
\hline Item 14 & 0.74 & 0.86 \\
\hline \multirow[t]{2}{*}{ Item 15} & 0.83 & 0.86 \\
\hline & \multicolumn{2}{|c|}{ Continued use despite social or interpersonal problems } \\
\hline Item 9 & 0.62 & 0.87 \\
\hline Item 21 & 0.63 & 0.85 \\
\hline \multirow[t]{2}{*}{ Item 35} & 0.78 & 0.85 \\
\hline & \multicolumn{2}{|c|}{ Failure to fulfil major role obligations } \\
\hline Item 19 & 0.51 & 0.85 \\
\hline \multirow[t]{2}{*}{ Item 27} & 0.77 & 0.85 \\
\hline & \multicolumn{2}{|c|}{ Eating certain foods in physically hazardous situations } \\
\hline Item 28 & 0.75 & 0.88 \\
\hline Item 33 & 0.79 & 0.87 \\
\hline \multirow[t]{2}{*}{ Item 34} & 0.78 & 0.87 \\
\hline & \multicolumn{2}{|c|}{ Craving, or a strong desire or urge to eat certain food } \\
\hline Item 29 & 0.80 & 0.85 \\
\hline \multirow[t]{2}{*}{ Item 30} & 0.82 & 0.86 \\
\hline & \multicolumn{2}{|c|}{ Clinically significant impairment or distress } \\
\hline Item 16 & 0.84 & 0.87 \\
\hline Item 17 & 0.72 & 0.87 \\
\hline
\end{tabular}




\begin{tabular}{|c|c|c|c|}
\hline Individual YFAS symptom & ICC & $95 \% \mathrm{CI}$ & Spearman $\rho$ \\
\hline Food taken in larger amount and for longer period than intended & 0.92 & $0.91-0.94$ & 0.93 \\
\hline Persistent desire or repeated unsuccessful attempts to quit & 0.71 & $0.66-0.76$ & 0.73 \\
\hline Much time/activity to obtain, use or recover from effects of food & 0.82 & $0.79-0.85$ & 0.83 \\
\hline Important social, occupational, or recreational activities given up or reduced & 0.60 & $0.54-0.66$ & 0.64 \\
\hline Use continues despite knowledge of adverse consequences & 0.81 & $0.77-0.84$ & 0.82 \\
\hline Tolerance & 0.78 & $0.74-0.82$ & 0.79 \\
\hline Withdrawal & 0.70 & $0.64-0.74$ & 0.71 \\
\hline Continued use despite social or interpersonal problems & 0.76 & $0.72-0.80$ & 0.77 \\
\hline Failure to fulfil major role obligations & 0.72 & $0.68-0.77$ & 0.73 \\
\hline Eating certain foods in physically hazardous situations & 0.83 & $0.79-0.85$ & 0.83 \\
\hline Craving, or a strong desire or urge to eat certain food & 0.87 & $0.84-0.89$ & 0.86 \\
\hline Clinically significant impairment or distress & 0.85 & $0.83-0.88$ & 0.88 \\
\hline Total symptom score & 0.93 & $0.91-0.94$ & 0.94 \\
\hline YFAS food addiction diagnosis & 0.95 & $0.94-0.96$ & 0.95 \\
\hline
\end{tabular}

$\mathrm{P}<0.001$ for all items.

ICC = intraclass correlation coefficient.

CI = confidence interval.

or nominal ratings. The YFAS 2.0 has 8 ordered response categories for each item. Disagreements between the English and Arabic YFAS 2.0 versions as regards these categories may not be all of the same importance. For example, a disagreement between a student's ratings on the 2 scale versions that differed by a small amount on a given item should be considered less important than if the 2 scores were farther apart on this item. To deal with this situation, weighted kappa is more relevant as it takes into account the different levels of disagreement between item ordered categories. The most commonly used weights are the linear weights, which are proportional to the deviation of individual ratings, and the quadratic weights, which are proportional to the square of the deviations of the individual ratings. Although both weight types are criticized, mainly for being arbitrarily defined, they are widely used. In the current study, in which the number of categories of the scale items is large, we used the linear weights approach, as it is less sensitive than the quadratic weights to the number of categories (28). Our comparison between the Arabic and English versions showed good to very good agreement (weighted kappa statistics ranged from 0.66 to $0.95 ; P<0.001$ ).

Therefore, this study suggests that the Arabic YFAS 2.0-A is a reliable tool, and that it is valid for use as equivalent to the English YFAS 2.0 in the investigation of food addiction among Arabic speaking populations.

There were a few limitations in this research. Generalizability of the results is limited by recruiting participants by convenience sampling from a single medical college. All the students we recruited were apparently healthy and mostly were within normal weight range. Because they are bilingual, these students may not be representative of the monolingual Arabicspeaking populations for whom the translated scale version is intended. Future validation studies of the YFAS 2.0-A should include other populations, particularly patients with eating disorders, obesity, diabetes, and other conditions potentially associated with food addiction. In such clinical settings, the sensitivity and the specificity of the YFAS 2.0 can be ascertained against semistructured interviews. A further limitation in the current study is the calculation of the BMI from the self-reported height and weight rather than from actual measurements. For the original English YFAS and the updated YFAS 2.0 versions, the 1-factorial solution was established $(3,16)$. To determine whether the 1-factorial solution could be replicated for the Arabic version, future studies need to be larger to perform acceptable confirmatory factor analysis.

\section{Conclusion}

Interest in the study of food addiction has dramatically increased since the development of the well validated YFAS. The scale has been translated and cross-culturally validated in many languages. The YFAS 2.0, which has appeared to keep up with the update of the DSM-5, replicated the excellent psychometric properties of the original and other translated versions. Our findings suggest that the translated and adapted Arabic version (YFAS 2.0-A) of the YFAS 2.0 is a reliable tool, valid for use in the investigation of food addiction among Arabic-speaking populations. 
Table 3 Comparison between scores on the Arabic (YFAS 2.0 - A) and English (YFAS 2.0 - E) versions of the Yale Food Addiction Scale 2.0

\begin{tabular}{|c|c|c|c|c|}
\hline Item & $\begin{array}{l}\text { YFAS 2.0 - A } \\
\text { Mean (SD) }\end{array}$ & $\begin{array}{l}\text { YFAS 2.0 - E } \\
\text { Mean (SD) }\end{array}$ & $\mathbf{K}$ & Agreement \\
\hline \multicolumn{5}{|c|}{ Food taken in larger amount and for longer period than intended } \\
\hline 1 & $0.09(0.20)$ & $0.10(0.21)$ & 0.74 & Good \\
\hline 2 & $0.12(0.23)$ & $0.11(0.22)$ & 0.88 & Very good \\
\hline 3 & $0.10(0.21)$ & $0.08(0.24)$ & 0.86 & Very good \\
\hline \multicolumn{5}{|c|}{ Persistent desire or repeated unsuccessful attempts to quit } \\
\hline 4 & $0.06(0.14)$ & $0.05(0.16)$ & 0.66 & Good \\
\hline 25 & $0.04(0.05)$ & $0.03(0.06)$ & 0.70 & Good \\
\hline 31 & $0.08(0.17)$ & $0.08(0.18)$ & 0.84 & Very good \\
\hline 32 & $0.03(0.08)$ & $0.02(0.09)$ & 0.76 & Good \\
\hline \multicolumn{5}{|c|}{ Much time/activity to obtain, use or recover from effects of food } \\
\hline 5 & $0.08(0.23)$ & $0.09(0.21)$ & 0.93 & Very good \\
\hline 6 & $0.04(0.10)$ & $0.03(0.09)$ & 0.87 & Very good \\
\hline 7 & $0.02(0.05)$ & $0.02(0.04)$ & 0.91 & Very good \\
\hline \multicolumn{5}{|c|}{ Important social, occupational, or recreational activities given up or reduced } \\
\hline 8 & $0.03(0.06)$ & $0.03(0.08)$ & 0.67 & Good \\
\hline 10 & $0.04(0.09)$ & $0.04(0.13)$ & 0.73 & Good \\
\hline 18 & $0.01(0.06)$ & $0.02(0.06)$ & 0.85 & Very good \\
\hline 20 & $0.02(0.05)$ & $0.02(0.05)$ & 0.77 & Good \\
\hline \multicolumn{5}{|c|}{ Use continues despite knowledge of adverse consequences } \\
\hline 22. & $0.09(0.16)$ & $0.07(0.20)$ & 0.78 & Good \\
\hline 23 & $0.07(0.15)$ & $0.06(0.16)$ & 0.82 & Very good \\
\hline \multicolumn{5}{|c|}{ Tolerance } \\
\hline 24 & $0.02(0.15)$ & $0.03(0.17)$ & 0.86 & Very good \\
\hline 26 & $0.04(0.14)$ & $0.05(0.15)$ & 0.89 & Very good \\
\hline \multicolumn{5}{|c|}{ Withdrawal } \\
\hline 11 & $0.02(0.09)$ & $0.03(0.11)$ & 0.76 & Good \\
\hline 12 & $0.06(0.16)$ & $0.06(0.19)$ & 0.71 & Good \\
\hline 13 & $0.03(0.05)$ & $0.03(0.07)$ & 0.83 & Very good \\
\hline 14 & $0.05(0.14)$ & $0.06(0.18)$ & 0.76 & Good \\
\hline 15 & $0.02(0.05)$ & $0.03(0.08)$ & 0.78 & Good \\
\hline \multicolumn{5}{|c|}{ Continued use despite social or interpersonal problems } \\
\hline 9 & $0.05(0.12)$ & $0.06(0.15)$ & 0.89 & Very good \\
\hline 21 & $0.03(0.05)$ & $0.03(0.07)$ & 0.93 & Very good \\
\hline 35 & $0.07(0.20)$ & $0.07(0.19)$ & 0.91 & Very good \\
\hline \multicolumn{5}{|c|}{ Failure to fulfil major role obligations } \\
\hline 19 & $0.03(0.04)$ & $0.01(0.07)$ & 0.77 & Good \\
\hline 27 & $0.05(0.15)$ & $0.05(0.21)$ & 0.87 & Very good \\
\hline \multicolumn{5}{|c|}{ Eating certain foods in physically hazardous situations } \\
\hline 28 & $0.05(0.14)$ & $0.05(0.18)$ & 0.90 & Very good \\
\hline 33 & $0.06(0.16)$ & $0.09(0.22)$ & 0.86 & Good \\
\hline 34 & $0.04(0.06)$ & $0.04(0.08)$ & 0.92 & Very good \\
\hline \multicolumn{5}{|c|}{ Craving, or a strong desire or urge to eat certain food } \\
\hline 29 & $0.05(0.17)$ & $0.06(0.24)$ & 0.85 & Good \\
\hline 30 & $0.05(0.12)$ & $0.06(0.15)$ & 0.86 & Good \\
\hline \multicolumn{5}{|c|}{ Clinically significant impairment or distress } \\
\hline 16 & $0.06(0.13)$ & $0.06(0.15)$ & 0.93 & Very good \\
\hline 17 & $0.04(0.10)$ & $0.04(0.13)$ & 0.94 & Very good \\
\hline \multicolumn{5}{|c|}{ Total symptom score } \\
\hline & $1.74(4.25)$ & $1.76(4.97)$ & 0.95 & Very good \\
\hline
\end{tabular}

$\mathrm{K}=$ weighted kappa.

$\mathrm{P}<0.001$ for all. 


\section{Acknowledgements}

We would like to thank Ashley Gearhardt for her kind permission to translate and use the YFAS 2.0 and for providing us with helpful material. We would also like to thank our colleagues in the Psychiatry Department at Zagazig University. We thank, in particular, Professor Rafik Reda and Professor Wail Abu-Hindi for their great help and valuable suggestions throughout the study.

Funding: None.

Competing interests: None declared.

\section{Validation d'une version arabe de la Yale Food Addiction Scale 2.0 (YFAS 2.0) \\ Résumé}

Contexte : La Yale Food Addiction Scale (YFAS) est la référence absolue pour l'évaluation de l'addiction à la nourriture selon les critères du Manuel diagnostique et statistique des troubles mentaux (DSM). La version 2.0 de la YFAS a été publiée début 2016 afin de tenir compte de la mise à jour du DSM-5.

Objectif : La présente étude avait pour objet de traduire, d'adapter et de valider la DSM-5 YFAS 2.0 pour qu'elle puisse être utilisée par des locuteurs arabes.

Méthodes : Le questionnaire final en arabe (YFAS 2.0-A), mis au point à l'aide d'une méthodologie rigoureuse, ainsi que le questionnaire anglais (YFAS 2.0) ont tous deux été remplis par 236 étudiants de médecine égyptiens parlant couramment l'anglais et l'arabe. Trois semaines plus tard, le questionnaire YFAS 2.0-A a été soumis de nouveau à l'ensemble des participants.

Résultats : Le coefficient alpha de Cronbach pour le questionnaire YFAS 2.0-A était de 0,89. Les coefficients de corrélation intraclasse à trois semaines des scores de diagnostic et de symptômes étaient, respectivement, de 0,95 et 0,93. Les scores kappa pondérés étaient compris entre 0,66 et $0,95(p<0,001)$.

Conclusions : Nos résultats indiquent que la version arabe de la YFAS 2.0-A est un outil fiable et qu'elle peut être utilisée comme équivalent du questionnaire anglais YFAS 2.0 pour étudier l'addiction à la nourriture dans les populations arabophones.

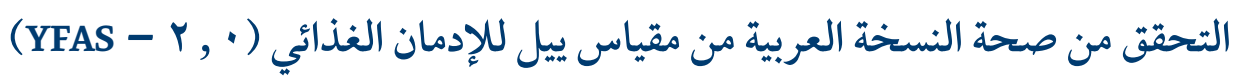

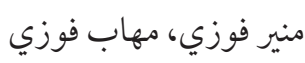
الخلاصة

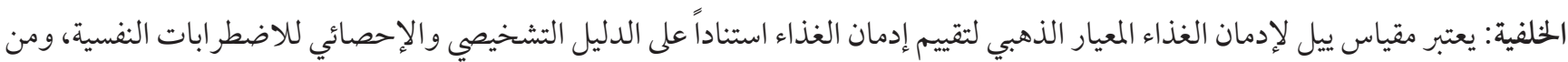

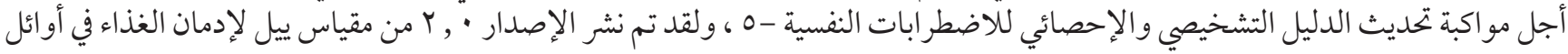
عام 17. الهدف: أجرينا الدر اسة الحالية حول الترجمة والتكييف والتحقق من صحة الترجمة لمقياس ييل للإدمان الغذائي · , ب استناداً إلى الدليل التشخيصي والإحصائي للاضطر ابات النفسية -0 ليستخدمه الناطقون باللغة العربية.

طرق البحث: لقد تم إعداد كل من مقياس ييل للإدمان الغذائي · , ب والدليل التشخيصي والإحصائي للاضطرابات النفسية -ه باتباع منهجية

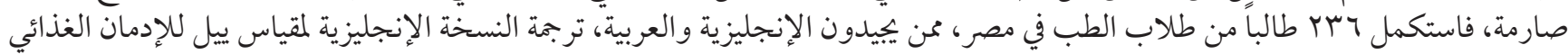

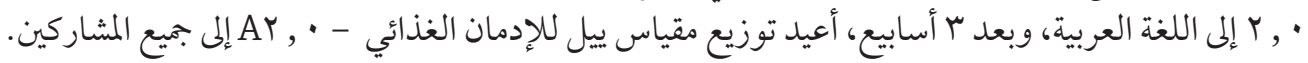

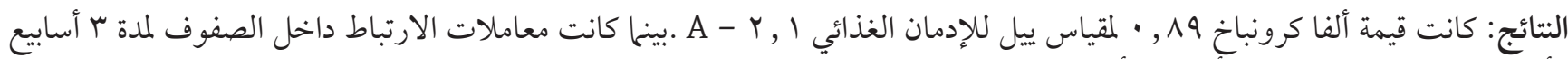

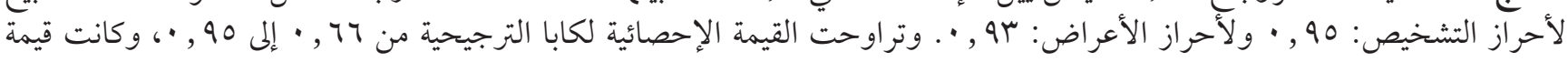
$(\cdot, \cdots)$ p)

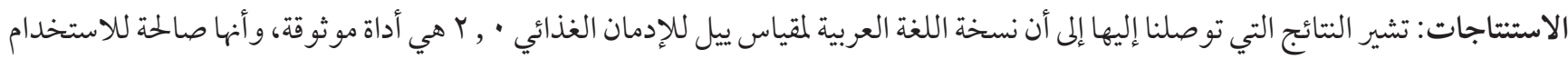

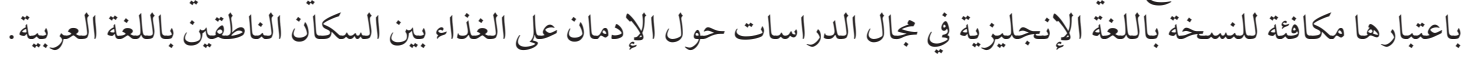




\section{References}

1. Cocores JA, Gold MS. The Salted Food Addiction Hypothesis may explain overeating and the obesity epidemic. Med Hypotheses. 2009;73:892-9. PMID:19643550

2. Randolph TG. The descriptive features of food addiction; addictive eating and drinking. Q J Stud Alcohol. 1956;17(2):198-224. PMID:13336254

3. Gearhardt AN, Corbin WR, Brownell KD. Preliminary validation of the Yale Food Addiction Scale. Appetite. 2009;52(2):430-6. PMID:19121351

4. Gearhardt AN, Davis C, Kuschner R, Brownell KD. The addiction potential of hyperpalatable foods. Curr Drug Abuse Rev. 2011;4(3):140-5. PMID:21999688

5. Diagnostic and statistical manual of mental disorders text revision. (4th ed., DSM-IV-TR). Washington, D.C: American Psychiatric Association; 2000.

6. Pursey KM, Collins CE, Stanwell P, Burrows TL. The stability of 'food addiction' as assessed by the Yale Food Addiction Scale in a non-clinical population over 18-months. Appetite. 2016;96:533-8. PMID:26482284

7. Clark SM, Saules KK. Validation of the Yale Food Addiction Scale among a weight-loss surgery population. Eat Behav. 2013;14(2):216-9. PMID:23557824

8. Gearhardt AN, White MA, Masheb RM, Morgan PT, Crosby RD, Grilo CM. An examination of the food addiction construct in obese patients with binge eating disorder. Int J Eat Disord. 2012;45(5):657-63. PMID:22684991

9. Dimitrijević I, Popović N, Sabljak V, Škodrić-Trifunović V, Dimitrijević N. Food addiction-diagnosis and treatment. Psychiatr Danub. 2015;27(1):101-6. PMID:22684991

10. Brunault P, Ballon N, Gaillard P, Réveillère C, Courtois R. Validation of the French version of the Yale food addiction scale: an examination of its factor structure, reliability, and construct validity in a nonclinical sample. Can J Psychiatry. 2014;59(5):276-84. PMID:25007281

11. Meule A, Heckel D, Kübler A. Factor structure and item analysis of the Yale Food Addiction Scale in obese candidates for bariatric surgery. Eur Eat Disord Rev. 2012;20(5):419-22. PMID:22761046

12. Granero R, Hilker I, Agüera Z, Jiménez-Murcia S, Sauchelli S, Islam MA, et al. Food addiction in a Spanish sample of eating disorders: DSM-5 diagnostic subtype differentiation and validation data. Eur Eat Disord Rev. 2014;22(6):389-96. PMID:25139680

13. Innamorati M, Imperatori C, Manzoni GM, Lamis DA, Castelnuovo G, Tamburello A, et al. Psychometric properties of the Italian Yale Food Addiction Scale in overweight and obese patients. Eat Weight Disord. 2015;20(1):119-27. PMID:25069837

14. Chen G, Tang Z, Guo G, Liu X, Xiao S. The Chinese version of the Yale Food Addiction Scale: An examination of its validation in a sample of female adolescents. Eat Behav. 2015;18:97-102. PMID:26026613

15. The diagnostic and statistical manual of mental disorders, 5th ed. (DSM-5), Washington, D.C: American Psychiatric Association; 2013.

16. Gearhardt AN, Corbin WR, Brownell KD. Development of the Yale Food Addiction Scale Version 2.o. Psychol Addict Behav. 2016;30(1):113-21. PMID:26866783

17. Meule A, Müller A, Gearhardt AN, Blechert J. German version of the Yale Food Addiction Scale 2.0: Prevalence and correlates of 'food addiction' in students and obese individuals. Appetite. 2016. pii: So195-6663(16)30505-0. doi: 10.1016/j.appet.2016.10.003. [Epub ahead of print] PMID:27717658

18. Brunault P, Courtois R, Gearhardt AN, Gaillard P, Journiac K, Cathelain S, et al. Validation of the French version of the DSM-5 Yale Food Addiction Scale in a nonclinical sample. Can J Psychiatry. 2017;62(3):199-210. PMID:28212499

19. Musaiger AO, Al-Hazzaa HM. Prevalence and risk factors associated with nutrition-related noncommunicable diseases in the Eastern Mediterranean region. Int J Gen Med. 2012;5:199-217. PMID:22399864

20. Abuyassin B, Laher I. Diabetes epidemic sweeping the Arab world. World J Diabetes. 2016;7(8):165-74. PMID:27114755

21. Musaiger AO. Overweight and obesity in the Eastern Mediterranean Region: can we control it? East Mediterr Health J. 2004;10(6):789-93.

22. Garduño-Diaz SD, Abu-Ghazaleh H. Addictive behaviour of dietary intake among young adults in Kuwait. EC Nutrition 2015; 2(3):348-50.

23. Naguib RM. Personality profile and affect regulation in relation to food addiction in a sample of obese females [thesis]. Cairo: Faculty of Medicine, Ain Shams University; 2014.

24. Fawzi MH, Fawzi MM, Abu-Hindi W. Arabic version of the Major Depression Inventory as a diagnostic tool: reliability and concurrent and discriminant validity. East Mediterr Health J. 2012;18(4):304-10. PMID:22768690

25. Nunnally JC, Bernstein J. Psychometric theory. New York, NY: McGraw Hill; 1994.

26. Portney LG, Watkins MP. Foundations of clinical research: applications to practice, 2nd ed. Upper Saddle River, NJ: Prentice Hall Health; 2000.

27. Altman, DG. Practical statistics for medical research. London: Chapman and Hall; 1991.

28. Brenner H, Kliebsch U. Dependence of weighted kappa coefficients on the number of categories. Epidemiology. 1996;7(2):199202. PMID:8834562 